\title{
Bi-Directional High-Conversion-Ratio CLLC Resonant Converter with a New Synchronous Rectification Scheme for Low Conduction Loss
}

\author{
Kai Sun ${ }^{* a)}$ Non-member, Yucheng Gao* Non-member \\ Huan Chen* Non-member
}

(Manuscript received June 28, 2019, revised April 9, 2020)

\begin{abstract}
This paper proposes a new synchronous rectification (SR) scheme for frequency-modulated bi-directional CLLC resonant converters. By introducing a small-phase-shift between the two full-bridges and utilizing the switching transient, the proposed scheme effectively avoids the magnetizing current being provided from the low voltage side. This leads to considerable reduction in the conduction losses and current stress of the switches in a high-step-down design. Furthermore, the output voltage characteristic is analyzed using a novel mathematical model, which, comparing to the fundamental harmonic approximation method, can not only acquire a more accurate result of steady-state characteristic, but also calculate an accurate set of initial values for the passive components, which is crucial to determine the proper dead-time and phase-shift. Based on the new model, the boundaries of dead-time and phase-shift are discussed in detail. Finally, a prototype is built, and experiments are conducted to verify the principles of the proposed scheme.
\end{abstract}

Keywords: CLLC resonant converter, phase shift, synchronous rectification, high-step-down

\section{Introduction}

Resonant full-bridge converter is a popular choice for highstep-down dc-dc conversion applications, due to its simplicity to achieve high conversion ratio and zero voltage switching (ZVS). Comparing to the common LLC converters, CLLC converter, as shown in Fig. 1(a), has a symmetrical feature desirable for bi-directional operations ${ }^{(1)-(4)}$, and is hence preferred in various applications, especially the emerging energy storage and dc distribution industries ${ }^{(5)-(8)}$.

In the conventional control scheme of CLLC resonant converters, the output rectifier switches are turned off and the anti-parallel diodes are utilized ${ }^{(1)(9)(10)}$. In this scheme, however, the bi-directional power transition speed is inevitably slow due to the transition of the drive signals. Moreover, in many cases, the diodes produce high conduction loss due to forward voltage drop and hence limit the converter efficiency. Synchronous rectification (SR) is an effective way to solve these issues, which has been widely applied in LLC resonant converters ${ }^{(11)-(17)}$. In literature ${ }^{(11)}$, a synchronous rectification method is proposed to make the on/off behavior of MOSFETs the same as the diode rectifier. In literature ${ }^{(12)}$, the synchronous rectification is used to deal with problems caused by parasitic parameters of the half bridge. In literature ${ }^{(13)}$, cutting down the cost of the synchronous rectification is the main target. In literature ${ }^{(14)}$, the synchronous rectification is realized by sending the same PWM signals to the primary and the secondary side. In literature ${ }^{(15)}$, a synchronous rectification method is proposed where PWM signals of the

a) Correspondence to: Kai Sun. E-mail: sun-kai@ tsinghua.edu.cn * State Key Lab of Power Systems, Tsinghua University

3-310, West Main Building, Tsinghua University, Haidian, Beijing 100084, China

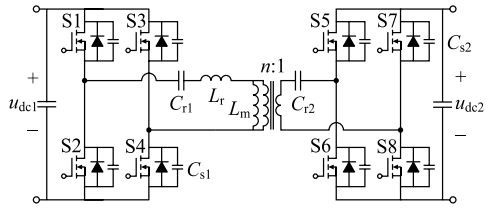

(a) basic topology

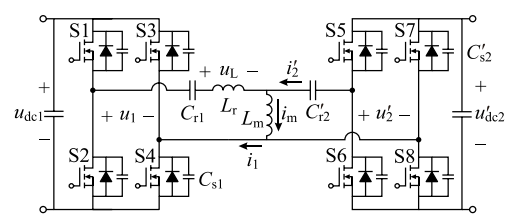

(b) normalized equivalent circuit

Fig. 1. Circuit of full-bridge CLLC resonant converter

secondary side lags behind that of the primary side. In literature $^{(16)}$, only the dead time of one of the two half bridges in secondary $\mathrm{H}$ bridge is extended. In literature ${ }^{(17)}$, PWM signals of the secondary side lags behind that of the primary side and the dead time of secondary side is larger. But still relevant discussions on the CLLC converters are limited.

Furthermore, the magnetizing current in the transformer must be kept at a certain amplitude for achieving ZVS in resonant converters ${ }^{(18)}$. But in a high-step-down design, as the transformer turns ratio is large, the magnetizing current will be significantly higher if the transformer is magnetized by the low voltage side than by the high voltage side, leading to increased copper loss and conduction loss.

This paper proposes a new SR scheme that has a promising capability of fast bi-directional power transition as well as ensuring the high voltage supply provides the magnetizing current. The target application is the two-stage energy storage system, where The CLLC converter is mainly used to 


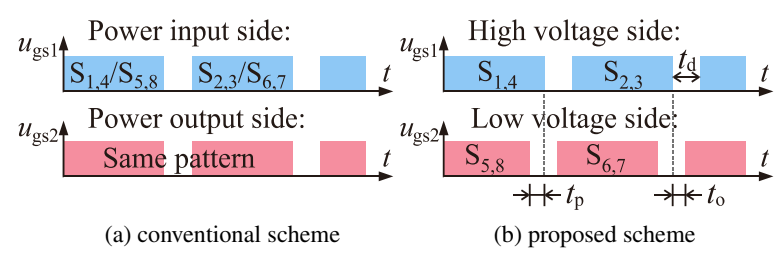

Fig. 2. Conventional and proposed SR schemes for CLLC converter

guarantee the high efficiency power conversation. Comparing to the traditional SR scheme, which shows inconsistency in the switching transient process of bi-directional operations, the proposed scheme utilizes the switching transient process. Specifically, the proposed scheme introduces a small phaseshift between the two full-bridges, as shown in Fig. 2. The word "small" refers to the condition that the phase-shift $t_{\mathrm{p}}$ is less than the dead-time $t_{\mathrm{d}}$. To guarantee the magnetizing current provided by the high voltage side in a high-step-down design, the drives on the low-voltage side are always leading.

This paper is an extension of(19), where the simulation and experimental results show disagreement with the first harmonics analysis-based results, and consequently the phase-shift and dead-time determination is not accurate enough. In addition, a similar idea to introduce phase-shift in the synchronous rectification for the CLLC converter is introduced in (20), but it is generally for half-bridge topology, and again, the gain analysis is based on first harmonics analysis method. In this paper, the principle of the switching transient under the proposed SR scheme is further analyzed. Then, a time domain-based analysis method for steady-state characteristics of the converter is introduced. Based on the improved model, the limitations of phase-shift and dead time are discussed. Furthermore, a $1 \mathrm{~kW}$ prototype is built, and the theoretical results are verified through experiments.

\section{Principle of Switching Transient}

The normalized equivalent circuit of a CLLC converter is illustrated in Fig. 1(b), where $L_{\mathrm{r}}, C_{\mathrm{r} 1}, C_{\mathrm{r} 2}$ compose a resonant tank with a resonant frequency of $f_{\mathrm{r}}$, and $L_{\mathrm{m}}$ is usually more than three times larger than $L_{\mathrm{r}}$. For the analysis of the switching transient, the following assumptions are made:

i. As $L_{\mathrm{m}}$ is significant than $L_{\mathrm{r}}$, the voltage on $L_{\mathrm{m}}$ is close to a square wave, and therefore, $i_{\mathrm{m}}$ is regarded as a triangular wave in a switching period, and is constant during switching transient;

ii. As the resonant period is far longer than the switching transient, the voltage variation of $C_{\mathrm{r} 1}, C_{\mathrm{r} 2}$ are neglected during the switching transient;

iii. Before the switching transients, the changing rates of $i_{1}$ and $i_{2}^{\prime}$ are generally low, and their influence is ignored in the switching transient analysis.

The switching transient when $u_{1}, u_{2}^{\prime}$ change from negative to positive is taken here as an example. According to the initial direction of $i_{2}^{\prime}$, two circumstances are discussed separately. The key waveforms are presented in Fig. 3, and the corresponding circuit diagrams are demonstrated in Fig. 4.

$2.1 \mathrm{i}_{2}{ }_{2}<0$ before Switching Transient Right before time $t_{0}$, the following conditions will be true: $u_{1}=-u_{\mathrm{dc} 1}$, $u_{2}^{\prime}=-u_{\mathrm{dc} 2}^{\prime}, \underline{i}_{\mathrm{m}}<0, u_{\mathrm{L}}$ is close to zero, and $\mathrm{S}_{2}, \mathrm{~S}_{3}, \mathrm{~S}_{6}$ and $\mathrm{S}_{7}$ are conducting.

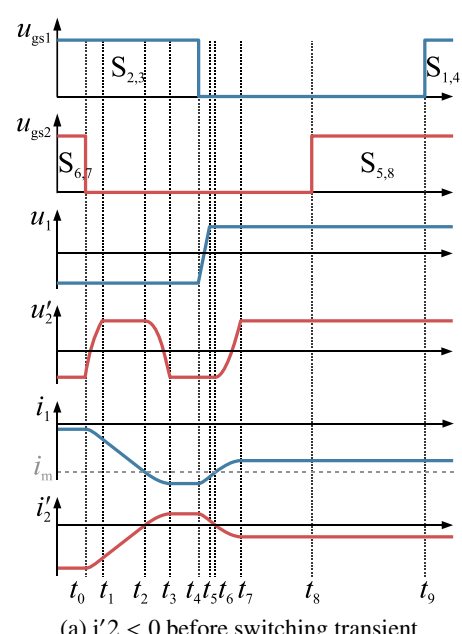

(a) $\mathrm{i}^{\prime} 2<0$ before switching transient

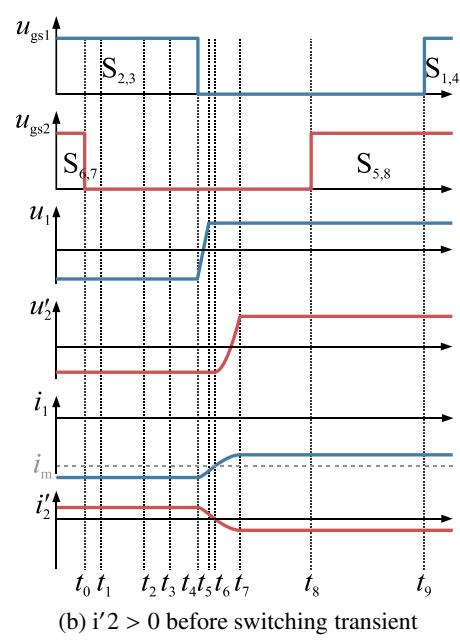

Fig. 3. Key waveforms of switching transient

Stage $1\left[t_{0}, t_{1}\right]$ : At time $t_{0}, \mathrm{~S}_{6} \& \mathrm{~S}_{7}$ are turned off. With the presence of $L_{\mathrm{m}}$ and $L_{\mathrm{r}}, i_{2}^{\prime}$ cannot have a step change and is hence negative, so it begins to charge the parasitic capacitance of $S_{6} \& S_{7}$ and discharge that of $S_{5} \& S_{8}$.

Stage $3\left[t_{2}, t_{3}\right]$ : At time $t_{2}, i_{2}^{\prime}$ reaches zero, so $D_{5} \& D_{8}$ are turned off, allowing $C_{\mathrm{s} 2}^{\prime}$ and $L_{\mathrm{r}}$ to resonate. In this interval, $i_{2}^{\prime}$ will continue rising, and $u_{2}^{\prime}$ starts to decrease.

Stage $2\left[t_{1}, t_{2}\right]$ : At time $t_{1}, u_{2}^{\prime}=u_{\mathrm{dc} 2}^{\prime}$, and then diodes $\mathrm{D}_{5}$ $\& \mathrm{D}_{8}$ are turned on. During this time period, $i_{2}^{\prime}$ increases at a high and constant rate, which is mainly decided by the voltage drop on $L_{\mathrm{s}}$ :

$$
\frac{\mathrm{d} i_{2}^{\prime}}{\mathrm{d} t}=\frac{u_{\mathrm{dcl}}+u_{\mathrm{dc}^{\prime}}}{L_{\mathrm{r}}}
$$

Stage $3\left[t_{2}, t_{3}\right]$ : At time $t_{2}, i_{2}^{\prime}$ reaches zero, so $\mathrm{D}_{5} \& \mathrm{D}_{8}$ are turned off, allowing $C_{\mathrm{s} 2}^{\prime}$ and $L_{\mathrm{r}}$ to resonate. In this interval, $i_{2}^{\prime}$ will continue rising, and $u_{2}^{\prime}$ starts to decrease.

Stage $4\left[t_{3}, t_{4}\right]$ : At time $t_{3}, u_{2}^{\prime}=-u_{\mathrm{dc} 2}^{\prime}$, so $u_{\mathrm{L}}$ becomes small again, and $i_{1}, i_{2}^{\prime}$ will only change at a very slow rate. Moreover, as $i_{\mathrm{m}}<0$ and $i_{2}^{\prime}>0$, there should be $i_{1}<0$, meaning that $\mathrm{S}_{2} \& \mathrm{~S}_{3}$ are conducting.

Stage $5\left[t_{4}, t_{5}\right]$ : At time $t_{4}, \mathrm{~S}_{2} \& \mathrm{~S}_{3}$ are turned off by the controller. Consequently, $i_{1}$ begins to charge/discharge the parasitic capacitance $C_{\mathrm{s} 1}$ of $\mathrm{S}_{1}-\mathrm{S}_{4}$.

Stage $6\left[t_{5}, t_{6}\right]$ : At time $t_{5}, u_{1}=u_{\mathrm{dc} 1}$, diodes $\mathrm{D}_{1} \& \mathrm{D}_{4}$ are turned on. According to the high and constant voltage added 


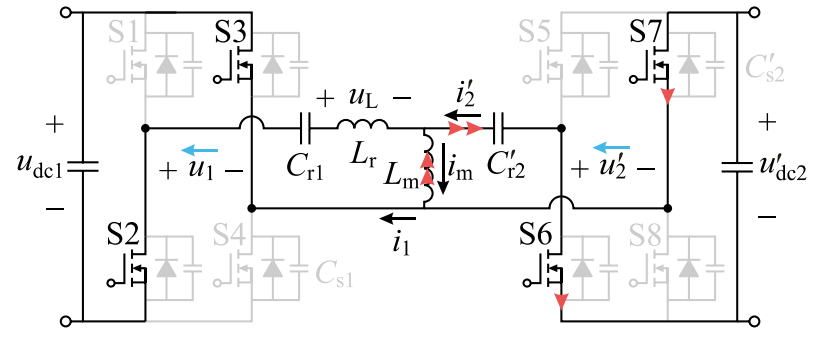

(a) circuit before switching transient

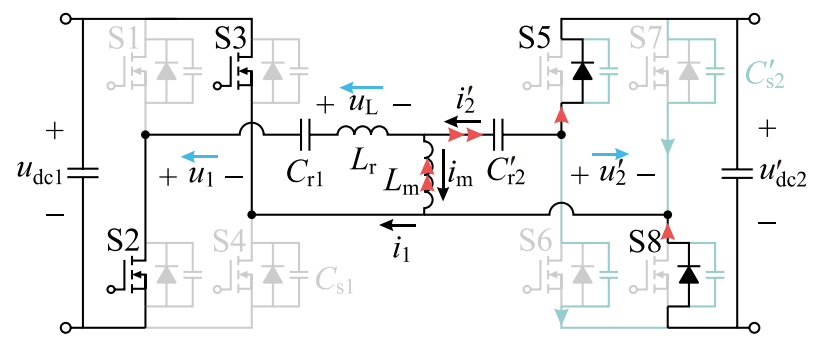

(b) during $t_{0}-t_{2}$

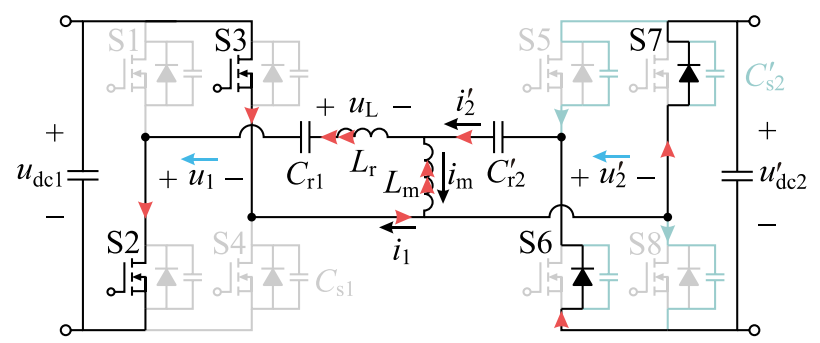

(c) during $t_{2}-t_{4}$

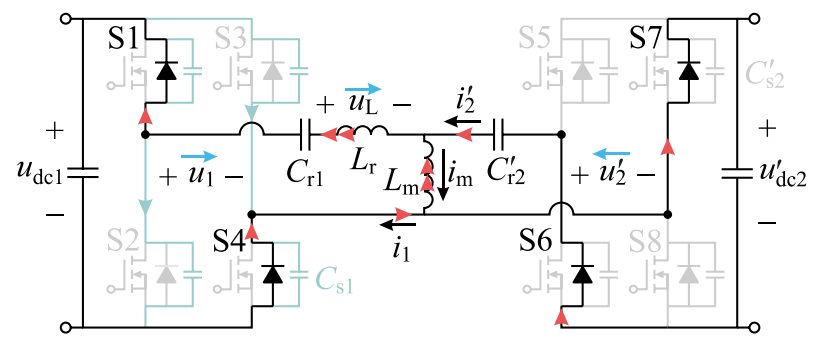

(d) during $t_{4}-t_{6}$

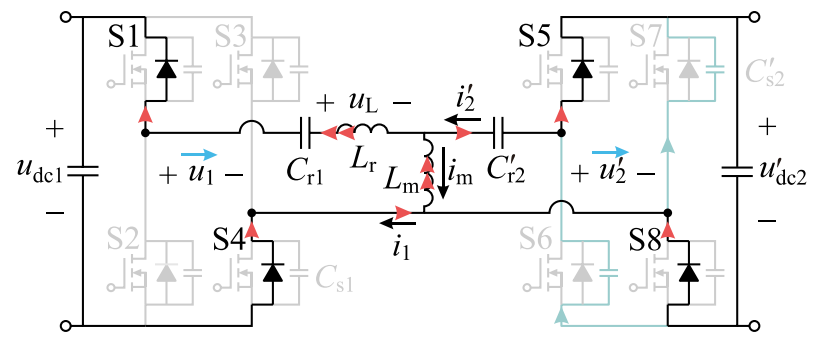

(e) during $t_{6}-t_{8}$

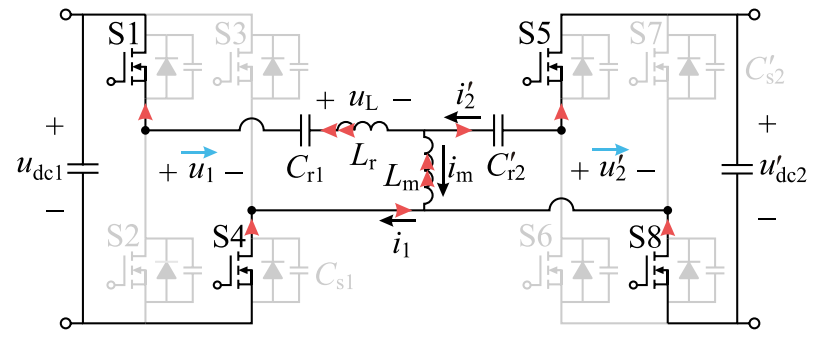

(f) circuit after $t_{9}$ when all transistors are turned on

Fig. 4. Key current paths and circuit diagrams during a switching transient for initial value of $i^{\prime} 2$ is negative. Directions of currents are marked by red arrows, and directions of voltage drops are marked by blue arrow

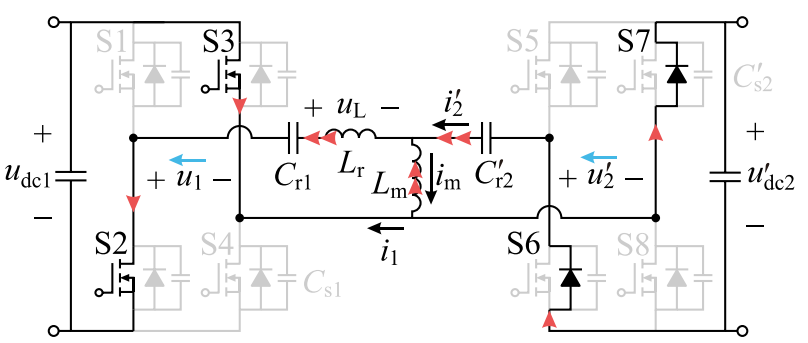

Fig. 5. Key current paths and circuit diagrams during a switching transient during t0-t4 for initial value of $i^{\prime} 2$ is positive

on $L_{\mathrm{r}}, i_{1}$ will decrease and $i_{2}^{\prime}$ will increase at a high and constant rate, at a value opposite to that of (1).

Stage $7\left[t_{6}, t_{7}\right]$ : At time $t_{6}, i_{2}^{\prime}$ reaches zero, so $\mathrm{D}_{6} \& \mathrm{D}_{7}$ are turned off and, after another charging process, $D_{5} \& D_{8}$ are turned on. The resonant process of $C_{\mathrm{s} 2}^{\prime}$ and $L_{\mathrm{s}}$ decides the final current:

$$
i_{2}^{\prime}=-2 u_{d \mathrm{~d}} \sqrt{C_{\mathrm{s} 2}^{\prime} / L_{\mathrm{r}}}
$$

Stage $8\left[t_{7}, t_{8}\right]$ : During this stage, $i_{1}, i_{2}^{\prime}$ will be changing at a very slow rate, and ideally $i_{2}^{\prime}$ will still be negative at the end of this period.

Stage $9\left[t_{8}, t_{9}\right]$ : At time $t_{8}$, since $\mathrm{D}_{5} \& \mathrm{D}_{8}$ are on right before time $t_{8}, \mathrm{~S}_{5} \& \mathrm{~S}_{8}$ can be turned on under ZVS condition.

Stage 10: At time $t_{9}$, ZVS turning-on can be achieved for $\mathrm{S}_{1} \& \mathrm{~S}_{4}$

$2.2 \mathbf{i}_{2}{ }_{2}>0$ before Switching Transient If $i_{2}^{\prime}>0$, then at time $t_{0}$ the current will switch from $\mathrm{S}_{6} \& \mathrm{~S}_{7}$ to $\mathrm{D}_{6}$ $\& \mathrm{D}_{7}$, and $u_{2}^{\prime}$ will not change. Before $\mathrm{S}_{2} \& \mathrm{~S}_{3}$ turn off, the status is the same to that of Stage 4 in part A, as shown in Fig. 5. Then, the system will respond as $\left[t_{4}, t_{9}\right]$ described in the previous part.

In summary, for both cases, the switching transient ends at time $t_{7}$, when $i_{2}^{\prime}$ equals to the value specified in (2), which can usually be considered as a very small value. Therefore, when the converter is modulated at a switching frequency $f_{\mathrm{s}}$ close to $f_{\mathrm{r}}$, which means the current waveforms of the inverter and the rectifier are approximately sinusoidal, the switching transient analyzed above will guarantee that the ac current of the low voltage side is in phase with the corresponding ac voltage. Consequently, the low voltage side will provide almost zero reactive power, and the transformer is fully magnetized by the high voltage side.

\section{Steady-State Characteristic}

In previous work on resonant converters, the currents in the resonant tank are approximated as simply sinusoidal waves at the resonant frequency, and a fundamental frequency simplification is applied to the analysis of steady-state characteristic $^{(19)}$. However, it is very common that $L_{\mathrm{m}}$ is less than ten times larger than $L_{\mathrm{r}}$, which will also result in a visible, lower-frequency sinusoidal term in the currents. In fact, when the switching frequency is significantly different to the resonant frequency, the solution acquired in (19) shows that there would be a notable phase-shift between the two ac voltages $u_{\mathrm{dc} 1}$ and $u_{\mathrm{dc} 2}$, which is incorrect since the phase-shift in the synchronous rectification scheme is very small.

It is desired to develop an improved analytical model for 


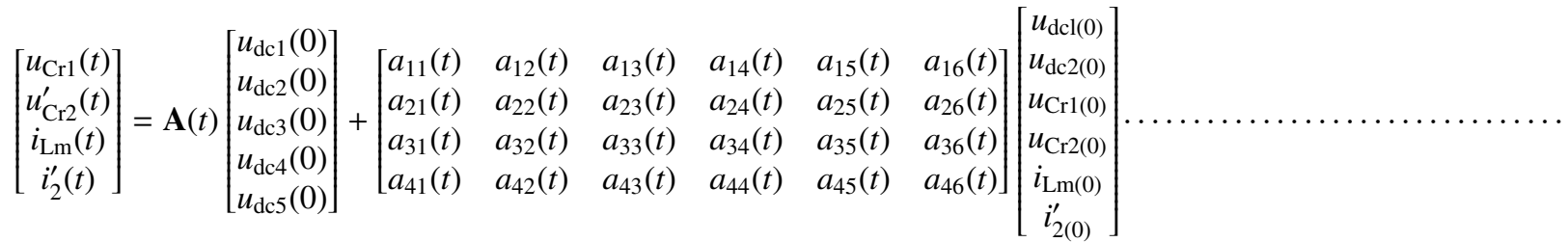

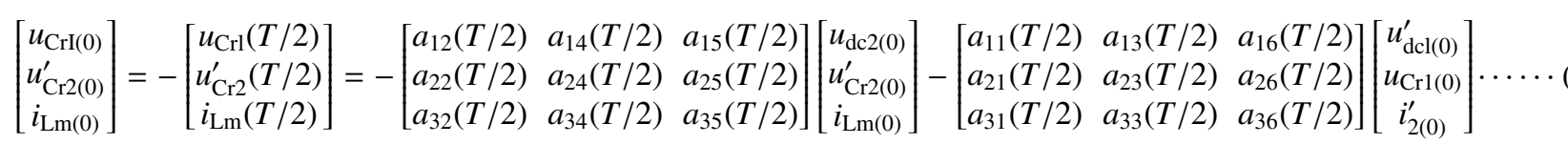

the proposed SR scheme, not only for a more accurate steadystate characteristics, but also for an accurate set of initial values for the passive components, which is crucial to determine the proper dead-time and phase-shift.

Therefore, in this study, a more accurate model based on the Laplace domain is proposed, where all the harmonics are included in the analytical result. In half of the switching period, $S_{1}, S_{4}, S_{5}$ and $S_{8}$ are constantly turned on, and the circuit becomes a simple network of impedances and capacitances. In this system, there are four state variables $i_{\mathrm{Lm}}, i_{\mathrm{Lr}}$, $u_{\mathrm{Cr} 1}, u_{\mathrm{Cr} 2}^{\prime}$, as well as two constant inputs $u_{\mathrm{dc} 1}$ and $u_{\mathrm{dc} 2}^{\prime}$. The characteristic equation of this circuit is

$$
\left(s^{2}-\omega_{1}^{2}\right) \cdot\left(s^{2}-\omega_{2}^{2}\right)=0 \cdot
$$

where

$$
\begin{aligned}
& \omega_{1}, \omega_{2}=\left[\frac{C_{\mathrm{r} 2}^{\prime} L_{\mathrm{m}}+C_{\mathrm{rl}}\left(L_{\mathrm{m}}+L_{\mathrm{r}}\right)}{2}\right. \\
& \pm \sqrt{\left.\left(\frac{C_{12}^{\prime} L_{\mathrm{m}}+C_{\mathrm{r} 1}\left(L_{\mathrm{m}}+L_{\mathrm{r}}\right)}{2}\right)-C_{\mathrm{r} 1} C_{\mathrm{r} 2}^{\prime} L_{\mathrm{m}} L_{\mathrm{r}}\right]^{0.5}}
\end{aligned}
$$

The characteristic equation indicates that the step response $r$ of any input $u$ (either input $u_{\mathrm{dc} 1}, u_{\mathrm{dc} 2}^{\prime}$ or the initial value of $i_{\mathrm{Lm}}, i_{\mathrm{Lr}}, u_{\mathrm{Cr} 1}, u_{\mathrm{Cr} 2}^{\prime}$ ) has only a dc term and two sinusoidal terms with a frequency of $\omega_{1}$ and $\omega_{2}$, which could be written as

$$
r(t)=\left[a_{1} \sin \left(\omega_{1} t+\varphi_{1}\right)+a_{2} \sin \left(\omega_{2} t+\varphi_{2}\right)+a_{3}\right] u(t)
$$

where $a_{1}, a_{2}, a_{3}, \phi_{1}$ and $\phi_{2}$ can be determined either analytically, or numerically by simulation and curve fitting. In this particular problem, the time domain equation can be written as

where

$$
\begin{aligned}
A(t)= & A_{1} \sin \left(\omega_{1} t\right)+A_{2} \cos \left(\omega_{1} t\right)+A_{3} \sin \left(\omega_{2} t\right) \\
& +A_{4} \cos \left(\omega_{2} t\right)+A_{5} \ldots \ldots \ldots \ldots \ldots \ldots \ldots \ldots \ldots \ldots
\end{aligned}
$$

Then, by performing an analysis on the half switching period when $u_{1}$ and $u_{2}^{\prime}$ are constants and positive, the steadystate output voltage $u_{\mathrm{dc} 2}^{\prime}$ characteristic can be acquired. Specifically, a set of linear equations about the initial values $i_{\mathrm{Lm}, 0}, i_{\mathrm{Lr}, 0}, u_{\mathrm{Cr} 1,0}, u_{\mathrm{Cr} 2,0}^{\prime}$ as well as $u_{\mathrm{dc} 2}^{\prime}$ can be listed based on the following conditions:

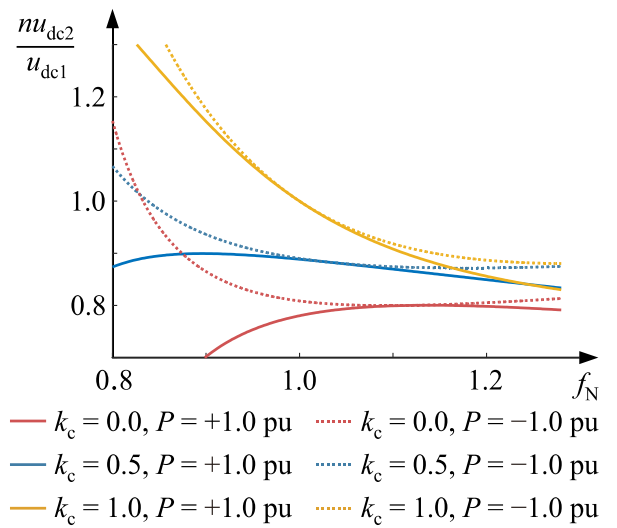

Fig. 6. Output voltage characteristic of the prototype converter

a. The final values (when $t=T_{\mathrm{s}} / 2$ ) of $i_{\mathrm{Lm}}, u_{\mathrm{Cr} 1}, u_{\mathrm{Cr} 2}^{\prime}$ are exactly opposite to their initial values;

b. $\quad i_{\mathrm{Lr}(0)}=i_{\mathrm{Lm}(0)}-i_{2(0)}^{\prime}$, where $i_{2(0)}^{\prime}$ is specified in (2);

The integral of $i_{\mathrm{Lr}}$ times $u_{\mathrm{dc} 1}$ in the half switching period equals to the input energy, which is $0.5 P f_{\mathrm{s}}$.

c. The integral of $i_{\mathrm{Lr}}$ times $u_{\mathrm{dc} 1}$ in the half switching period equals to the input energy, which is $0.5 P f_{\mathrm{s}}$.

In other words, the initial values of $u_{\mathrm{dc} 2(0)}, u_{\mathrm{Cr} 2(0)}^{\prime}$ and $i_{\mathrm{Lm}(0)}$ are acquired by solving the following equation:

where

$$
\begin{aligned}
& u_{\mathrm{dcl}(0)}=U_{\mathrm{dcl}} \ldots \ldots \ldots \ldots \ldots \ldots \ldots \ldots \ldots \ldots \ldots \ldots \ldots \ldots \ldots \\
& u_{\mathrm{Cr} 1(0)}=\frac{P U_{\mathrm{dc} 1}}{2 f_{\mathrm{S}} C_{\mathrm{r} 1}} \\
& i_{2(0)}^{\prime}=-2 u_{\mathrm{dc}} \sqrt{C_{\mathrm{s} 2}^{\prime} / L_{\mathrm{r}}}
\end{aligned}
$$

To demonstrate the relationship between the output voltage characteristic and circuit parameters, the following variables are introduced: $\lambda$ is the ratio of the magnetizing inductance to the resonant inductance, i.e., $\lambda=L_{\mathrm{m}} / L_{\mathrm{r}}$, and $k_{\mathrm{c}}$ is defined as $k_{\mathrm{c}}=C_{\mathrm{r} 1} /\left(C_{\mathrm{r} 1}+C_{\mathrm{r} 2} / n^{2}\right)$, which is ratio of the two capacitor impedances. Based on the full harmonic model, the frequency-gain curves of some sample circumstances are acquired, as demonstrated in Fig. 6, where $\lambda$ is set to 4 in all cases and $f_{N}$ is the normalized frequency. $f_{N}$ can be calculated as $f_{s} / f_{r} . f_{s}$ is the switching frequency and $f_{r}$ is the resonant frequency. The result is generally showing agreement with the fundamental harmonics analysis in (19). However, it can also be observed that the output voltage characteristic is more consistent regarding to power when $k_{\mathrm{c}}$ is high, 
Table 1. Parameters of CLLC Converter Prototype

\begin{tabular}{lll}
\hline \hline Symbol & \multicolumn{1}{c}{ QUANTITY } & \multicolumn{1}{c}{ Value } \\
\hline$U_{\mathrm{dc1}}$ & nominal input voltage & $520 \mathrm{~V}$ \\
$U_{\mathrm{dc} 2}$ & nominal output voltage & $70 \mathrm{~V}$ \\
$P_{0}$ & nominal power & $\pm 1.0 \mathrm{~kW}$ \\
$\mathrm{~S}_{1}-\mathrm{S}_{4}$ & high voltage switches & Cree C2M0080120D \\
$\mathrm{S}_{5}-\mathrm{S}_{8}$ & low voltage switches & Infineon IRFP4127 \\
$n$ & transformer turn ratio & $34: 5$ \\
$L_{\mathrm{r}}$ & leakage inductance & $150 \mu \mathrm{H}$ \\
$L_{\mathrm{m}}$ & magnetizing inductance & $550 \mu \mathrm{H}$ \\
$C_{\mathrm{r} 1}$ & resonant capacitor 1 & $0.1 \mu \mathrm{F}$ \\
$C_{\mathrm{r} 2}$ & resonant capacitor 2 & $8.0 \mu \mathrm{F}$ \\
$C_{\mathrm{s} 1}$ & Primary side switch $C_{\mathrm{oss}}$ & $58 \mathrm{pF}$ \\
$C_{\mathrm{s} 2}$ & Secondary side switch $C_{\mathrm{oss}}$ & $410 \mathrm{pF}$ \\
$f_{\mathrm{r}}$ & resonant frequency & $52 \mathrm{kHz}$ \\
\hline \hline
\end{tabular}

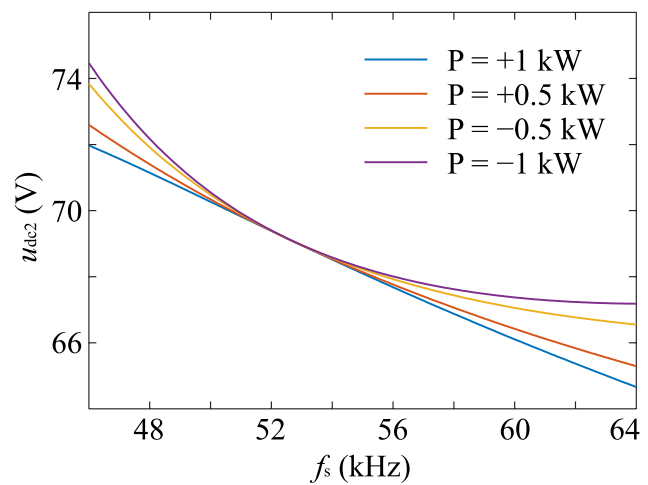

Fig. 7. Output voltage characteristic of the prototype converter

whereas it is highly dependent to load when $k_{\mathrm{c}}$ is low. Moreover, at low $k_{\mathrm{c}}$ it would be impossible to regulate the voltage under bi-directional power conditions, because the maximum voltage at $P=+1.0$ pu is equal to the minimum voltage at $P$ $=-1.0 \mathrm{pu}$. Therefore, it would be desired to keep $k_{\mathrm{c}}$ relatively large, so the output voltage regulation capability will be ensured. Furthermore, a CLLC converter with parameters given in Table 1 is taken as an example. The calculated output voltage $u_{\mathrm{dc} 2}^{\prime}$ versus $f_{\mathrm{s}}$ at several given $P$ is plotted in Fig. 7, which shows that for both power directions, the output voltage characteristics are generally close, and $u_{\mathrm{dc} 2}$ decreases as $f_{\mathrm{s}}$ increases.

\section{Phase-Shift and Dead-Time Restrictions}

A major feature of the proposed SR scheme is that the claimed benefit of having magnetizing current provided from the high voltage side can be achieved automatically, which does not require any high-accuracy sampling nor any complicated calculation. Still, there are certain restriction boundaries for the phase-shift and dead-time to ensure the proposed SR scheme works properly. According to the principle of operation discussed in Section II, the following two conditions must be satisfied:

a. $i_{2}^{\prime}$ must cross over zero during a switching transient, otherwise the reactive current will be supplied by the low voltage side.

b. $i_{2}^{\prime}$ must be negative right before $S_{5}$ and $S_{8}$ turn on to achieve ZVS.
To clearly demonstrate the restriction conditions, the following variables are defined as shown in Fig. 2: $t_{\mathrm{d}}$ is the dead time, $t_{\mathrm{p}}$ is the phase-shift time, and $t_{\mathrm{o}}=t_{\mathrm{d}}-t_{\mathrm{p}}$ is the overlap time. Then, based on the above two requirements, the time intervals of the switching transient must satisfy the following rules:

a. If the initial value of $i_{2}^{\prime}$ is negative, then $\left[t_{0}, t_{2}\right]$ should be sufficiently long to make $i_{2}^{\prime}$ reach zero. In the calculation, the time interval $\left[t_{0}, t_{1}\right]$ is neglected, and assume the current changes linearly during $\left[t_{1}, t_{2}\right]$, then the minimum $t_{\mathrm{p}}$ is solved:

$$
t_{\mathrm{p}, \text { min }}=-\frac{L_{\mathrm{r}} \cdot i_{2}^{\prime}(T / 2)}{u_{\mathrm{dcl}}+u_{\mathrm{dc} 2}^{\prime}}, \text { for } i_{2}^{\prime}(T / 2)<0 .
$$

b. $\left[t_{4}, t_{6}\right]$ should be sufficiently long to make $i_{2}^{\prime}$ reach zero. Here, since the current at the beginning of $t_{4}$ is low, the interval $\left[t_{4}, t_{5}\right]$ cannot be neglected, so firstly this interval needs to be calculated. By assuming the current charging and discharging the parasitic capacitance is equal to the magnetizing current, the time length and the variation of the current is acquired:

$$
\begin{aligned}
& t_{45}=t_{5}-t_{4}=-\frac{C_{\mathrm{s} 1}\left(u_{\mathrm{dcl}}+u_{\mathrm{dc} 2}^{\prime}\right)}{i_{\mathrm{Lm}(0)}} \\
& \Delta i_{2,45}^{\prime}=-\frac{t_{45}\left(u_{\mathrm{dc} 1}+u_{\mathrm{dc} 2}^{\prime}\right)}{L_{\mathrm{r}}} \ldots \ldots .
\end{aligned}
$$

Then, according to the sign of $i_{2}^{\prime}(T / 2)$, the minimum value of $t_{\mathrm{o}}$ is acquired:

$$
\begin{aligned}
& t_{0, \text { min }}=t_{45}-\frac{L_{\mathrm{r}}\left(i_{2}^{\prime}(T / 2)+\Delta i_{2,45}^{\prime}\right)}{u_{\mathrm{dcl}}+u_{\mathrm{dc} 2}^{\prime}}, \quad i_{2}^{\prime}(T / 2)>0 \\
& t_{0, \min }=t_{45}-\frac{L_{r}\left[\left(u_{\mathrm{c} 1}+u_{\mathrm{dc} 2}^{\prime}\right) \sqrt{C_{\mathrm{s} 2}^{\prime} / L_{\mathrm{r}}}+\Delta i_{2,45}^{\prime}\right]}{u_{\mathrm{dcl}}+u_{\mathrm{dc} 2}^{\prime}}, \\
& \text { for } i_{2}^{\prime}(\mathrm{T} / 2)<0
\end{aligned}
$$

c. If $P<0,\left[t_{7}, t_{8}\right]$ should be short enough so at $t=t_{8}$ there still has $i_{2}^{\prime}<0$. In other words, the maximum value of $t_{\mathrm{o}}$ is limited by:

$$
\begin{aligned}
& t_{0, \max }=\frac{\pi}{2} \sqrt{C_{s 2} L_{x}}+\frac{\left(u_{d c 1}+u_{\mathrm{dc} 2}^{\prime}\right) \sqrt{C_{s 2} / L_{r}}}{d i_{2}^{\prime}(T / 2) / d t}, \\
& \text { for } \frac{d i_{2}^{\prime}(T / 2)}{d t}>0 \ldots \ldots \ldots \ldots \ldots \ldots \ldots \ldots \ldots
\end{aligned}
$$

Furthermore, rules d-e are preferred to be satisfied:

d. $\left[t_{3}, t_{4}\right]$ should be as short as possible to shorten the transient process.

e. The times $t_{\mathrm{p}}$ and $t_{\mathrm{o}}$ should be close to rule a and $\mathrm{b}$, e.g., in $100 \mathrm{~ns}$, otherwise the lossy diodes will be conducting for a long time.

By applying rules a-e, the feasible boundaries of dead-time and phase-shift can be determined. As an example, the range of $t_{\mathrm{p}}$ and $t_{\mathrm{o}}$ versus $f_{\mathrm{s}}$ for the prototype converter (Table 1) at full power conditions are calculated, and the results are plotted in Fig. 8. The feasible range of $t_{\mathrm{p}}$ and $t_{\mathrm{o}}$ is highly dependent to $f_{\mathrm{s}}$ and $P$, but still it is possible to introduce a segmented function to determine a proper set of $t_{\mathrm{p}}$ and $t_{\mathrm{o}}$. 


\section{Experiment Verification}

A CLLC converter prototype is built, as shown in Fig. 9, with parameters given in Table 1 . The experimental waveforms of $u_{1}, u_{2}$ and $i_{2}$ are shown in Fig. 10, which clearly show that under the proposed SR scheme, the low-voltage side current $i_{2}$ is reset to zero after every switching transient, and consequently the reactive part of the current is significantly suppressed. The typical switching transient waveforms are provided in Fig. 11, where $t_{\mathrm{p}}$ and $t_{\mathrm{o}}$ are equal. The result shows consistency to the theoretical analysis in section II and the key waveforms in Fig. 3.

Furthermore, a set of constant-load, variable- $f_{\mathrm{s}}$ experiments under constant $u_{\mathrm{dc} 1}=520 \mathrm{~V}$ condition were implemented, where $u_{\mathrm{dc} 2}$ was measured, as plotted in Fig. 12. The result generally is observed in the experimental result, which

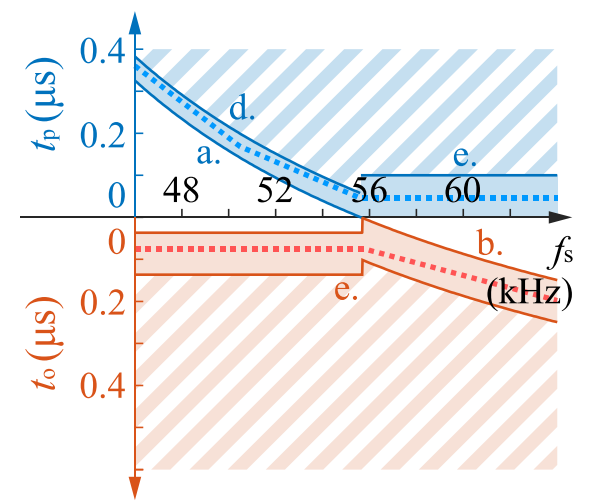

(a) $\mathrm{P}=+1 \mathrm{~kW}$

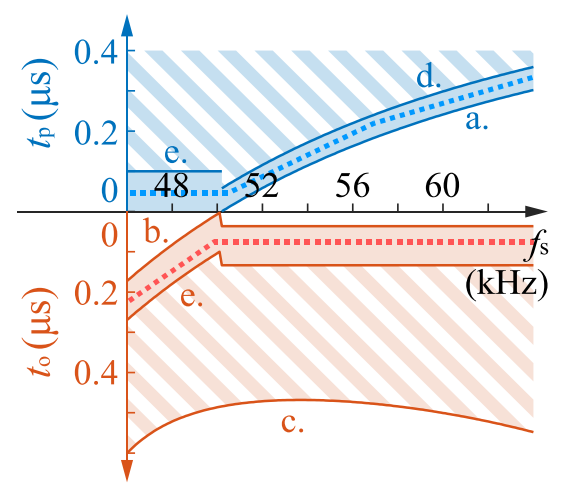

(b) $P=-1 \mathrm{~kW}$

Fig. 8. Feasible phase-shift time tp and overlap time to of the prototype converter. Solid color area: preferred range; shaded area: acceptable range; dotted line: one of the feasible tp and to versus fs segmented functions

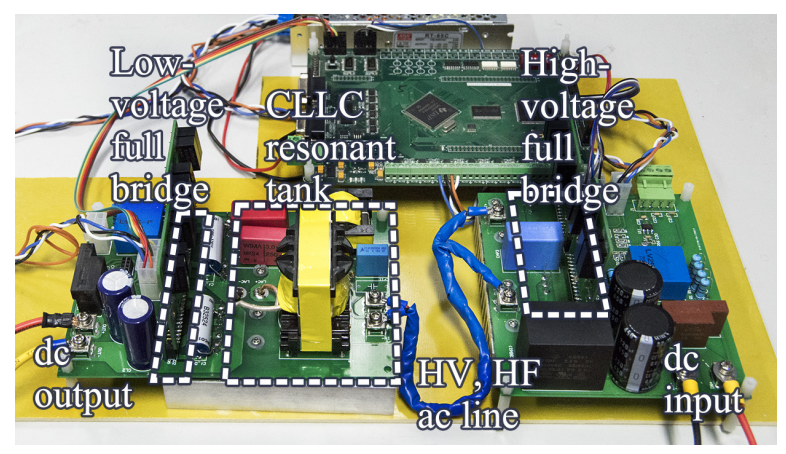

Fig. 9. Prototype of CLLC resonant converter is mainly caused by the voltage drop on MOSFETs and the inductor resistance. Moreover, there is a significant and important difference of the output-voltage characteristic between the two SR schemes: under the traditional scheme, $u_{\mathrm{dc} 2}$ can hardly reach the nominal $70 \mathrm{~V}$ value in all cases. The reason is that the source of $i_{\mathrm{m}}$ differs under $f_{\mathrm{s}}>f_{\mathrm{r}}$ and $f_{\mathrm{s}}<$

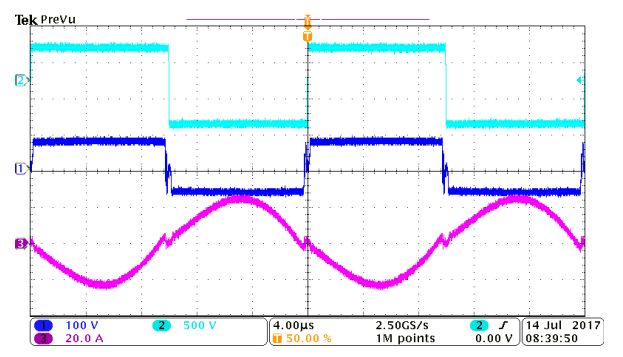

(a) proposed SR, $P=+1 \mathrm{~kW}, f_{\mathrm{s}}=50 \mathrm{kHz}$

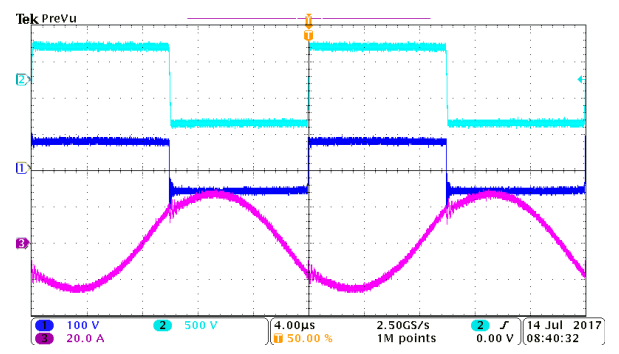

(b) conventional SR, $P=+1 \mathrm{~kW}, f_{\mathrm{S}}=50 \mathrm{kHz}$

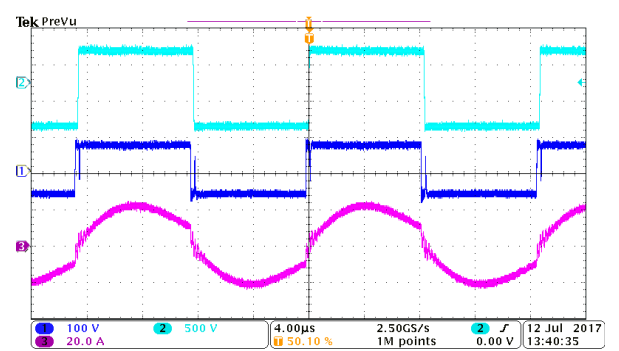

(c) proposed $\mathrm{SR}, P=-1 \mathrm{~kW}, f_{\mathrm{s}}=60 \mathrm{kHz}$

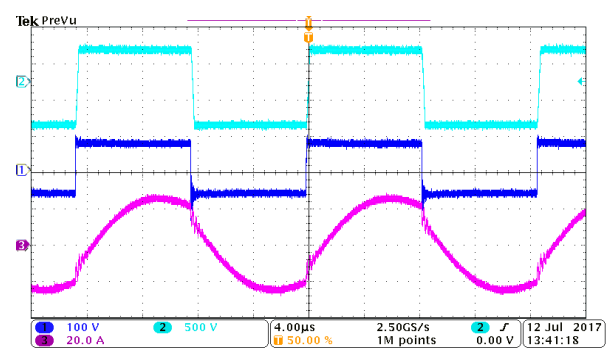

(d) conventional SR, $P=-1 \mathrm{~kW}, f_{\mathrm{s}}=60 \mathrm{kHz}$

Fig. 10. Experimental waveforms of conventional and proposed SR scheme. Cyan line: $u_{1}$; blue line: $u_{2}$; magenta line: $i_{2}$

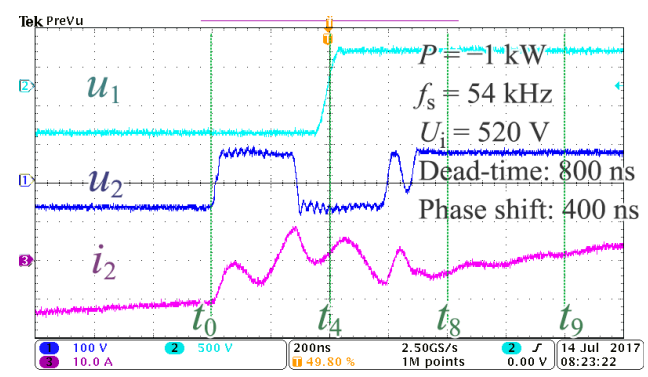

Fig. 11. Detail of the switching transient 


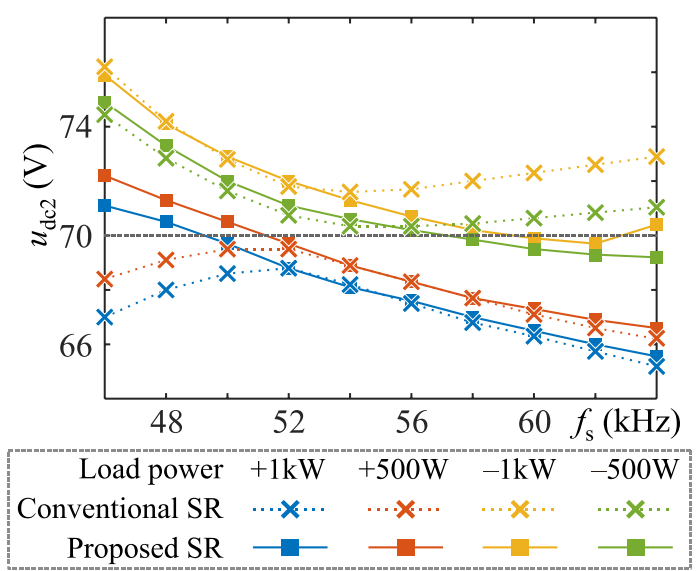

Fig. 12. Experiment result of output voltage $u_{\mathrm{dc2}}$ versus switching frequency $f_{\mathrm{s}}$

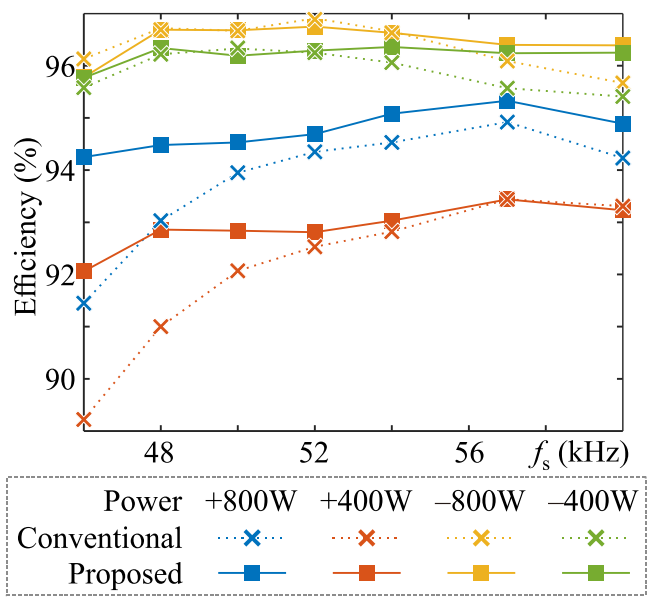

Fig. 13. Experiment result of efficiency versus switching frequency

$f_{\mathrm{r}}$ conditions, leading to different $f_{\mathrm{s}}-u_{\mathrm{dc} 2}$ characteristic with a limit of $u_{\mathrm{dc} 2}$ reached near $f_{\mathrm{s}}=f_{\mathrm{r}}$. The proposed scheme, however, has a unified $f_{\mathrm{s}}-u_{\mathrm{dc} 2}$ characteristic due to the constant source of magnetizing current, and consequently achieving an extended range of $u_{\mathrm{dc} 2}$, so the nominal output voltage can be achieved in all cases.

The measured efficiency versus switching frequency is plotted in Fig. 13. Furthermore, the efficiency-output voltage plot is presented in Fig. 14. In practical experimental implementation, we use different constant resistors as the load. The variation of "Approx. Power" is within $50 \mathrm{~W}$ which is relatively small and should not have big influence on efficiency comparison. For the measurement in Fig. 13 and Fig. 14, we use a multimeter to measure the voltage and current. The accuracy of the multimeter is $0.01 \mathrm{~V}$ and $0.01 \mathrm{~A}$. For the experimental prototype, the value of the input and output capacitors are large enough. So that the ripple of both current and voltage is small and should not have a big influence on efficiency. As a result, We just measure the DC component of the voltage and current and then calculate the efficiency. The figures indicate that at the same switching frequency and power, the proposed SR scheme achieves higher efficiency due to the reduced reactive current on the low voltage side. Consequently, given the same output voltage and power, the proposed SR scheme can generally achieve higher efficiency

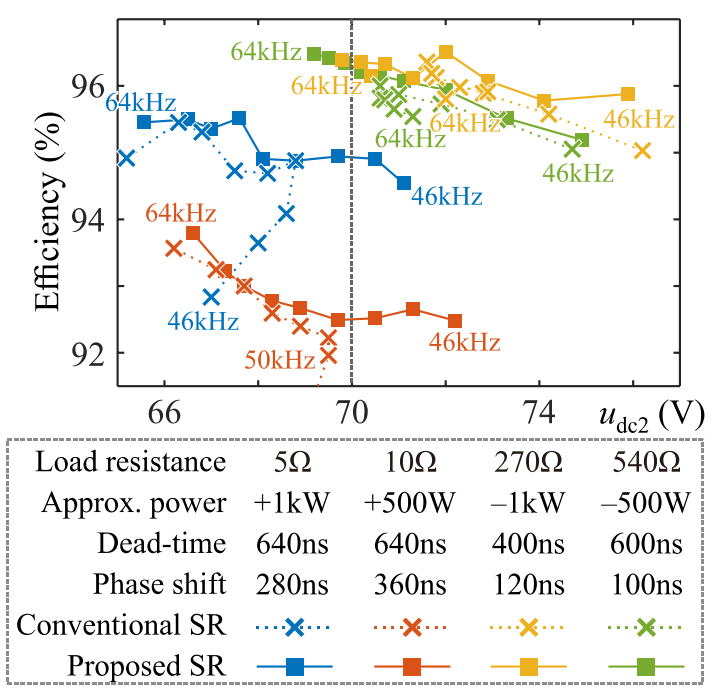

Fig. 14. Experiment result of efficiency versus output voltage

than the traditional SR scheme.

\section{Conclusion}

This paper has proposed a new SR scheme for bidirectional high-step-down CLLC converters. Utilizing the transient of a small phase shift between the full-bridges, this scheme successfully keeps the magnetizing current being constantly provided from the high voltage side and thus reduces conduction loss of the low voltage side. The principle of the switching transient has been analyzed and further verified by experiments. The steady-state voltage gain of the converter is generally consistent under different load and power direction, and thus it is possible to tune the output voltage to nominal value under bi-directional conditions. Still, the output voltage range is narrower than CLLC converters without $\mathrm{SR}$, and the transient process is highly dependent to the circuit parameters, including the non-linear output capacitance of MOSFETs, bringing complexity to the selection of deadtime and phase shift.

\section{Acknowledgment}

This work was supported in part by the National Natural Science Foundation of China under Grants 51877117, and in part by State Key Lab of Power Systems, Tsinghua University (SKLD18M06).

\section{References}

( 1 ) W. Chen, P. Rong, and Z. Lu: "Snubberless bidirectional DC-DC converter with new CLLC resonant tank featuring minimized switching loss", IEEE Transactions on Industrial Electronics, Vol.57, No.9, pp.3075-3086 (2010)

( 2 ) Y. Cai, C. Wang, F. Zhao, et al.: "Design of a high-frequency isolated DTHB CLLC bidirectional resonant DC-DC converter", in 2014 IEEE Conference and Expo Transportation Electrification Asia-Pacific (ITEC Asia-Pacific), Beijing, pp.1-6 (2014)

( 3 ) W.L. Malan, D.M. Vilathgamuwa, and G.R. Walker: "Modeling and Control of a Resonant Dual Active Bridge With a Tuned CLLC Network", IEEE Transactions on Power Electronics, Vol.31, No.10, pp.7297-7310 (2016)

( 4 ) S. Zhao, Q. Li, and F.C. Lee: "High frequency transformer design for modular power conversion from medium voltage AC to $400 \mathrm{~V}$ DC", in 2017 IEEE Applied Power Electronics Conference and Exposition, pp.2894-2901 (2017)

( 5 ) H.S. Kim, M.H. Ryu, J.W. Baek, and J.H. Jung: "High-Efficiency Isolated Bidirectional AC-DC Converter for a DC Distribution System", IEEE Transactions on Power Electronics, Vol.28, No.4, pp.1642-1654 (2013) 
( 6 ) J.H. Jung, H.S. Kim, M.H. Ryu, et al.: "Design Methodology of Bidirectional CLLC Resonant Converter for High-Frequency Isolation of DC Distribution Systems", IEEE Transactions on Power Electronics, Vol.28, No.4, pp.1741$1755(2013)$

( 7 ) Z.U. Zahid, Z.M. Dalala, R. Chen, et al.: "Design of Bidirectional DC-DC Resonant Converter for Vehicle-to-Grid (V2G) Applications", IEEE Transactions on Transportation Electrification, Vol.1, No.3, pp.232-244 (2015)

( 8 ) M.H. Ryu, H.S. Kim, J.W. Baek, et al.: "Effective Test Bed of 380-V DC Distribution System Using Isolated Power Converters", IEEE Transactions on Industrial Electronics, Vol.62, No.7, pp.4525-4536 (2015)

( 9 ) P. He and A. Khaligh: "Comprehensive Analyses and Comparison of $1 \mathrm{~kW}$ Isolated DC-DC Converters for Bidirectional EV Charging Systems", IEEE Transactions on Transportation Electrification, Vol.3, No.1, pp.147-156 (2017)

(10) C. Liu, J. Wang, K. Colombage, C. Gould, and B. Sen: "A CLLC resonant converter based bidirectional EV charger with maximum efficiency tracking", 8th IET International Conference on Power Electronics, Machines and Drives (PEMD 2016), Glasgow, pp.1-6 (2016)

(11) W. Feng, F.C. Lee, P. Mattavelli, and D. Huang: "A universal adaptive driving scheme for synchronous rectification in LLC resonant converters", IEEE Transactions on Power Electronics, Vol.27, No.8, pp.3775-3781 (2012)

(12) D. Fu, Y. Liu, F.C. Lee, and M. Xu: "A Novel Driving Scheme for Synchronous Rectifiers in LLC Resonant Converters", IEEE Transactions on Power Electronics, Vol.24, No.5, pp.1321-1329 (2009)

(13) J. Zhang, J. Wang, G. Zhang, and Z. Qian: "A Hybrid Driving Scheme for Full-Bridge Synchronous Rectifier in LLC Resonant Converter", IEEE Transactions on Power Electronics, Vol.27, No.11, pp.4549-4561 (2012)

(14) G.C. Hsieh, C.Y. Tsai, and W.L. Hsu: "Synchronous Rectification LLC Series-Resonant Converter", in 2007 IEEE Applied Power Electronics Conference and Exposition (APEC), Anaheim, CA, USA, pp.1003-1009 (2007)

(15) C. Duan, H. Bai, W. Guo, and Z. Nie: "Design of a 2.5-kW 400/12-V HighEfficiency DC/DC Converter Using a Novel Synchronous Rectification Control for Electric Vehicles", IEEE Transactions on Transportation Electrification, Vol.1, No.1, pp.106-114 (2015)

(16) L. Chen, H. Wu, P. Xu, H. Hu, and C. Wan: "A high step-down non-isolated bus converter with partial power conversion based on synchronous LLC resonant converter", in 2015 IEEE Applied Power Electronics Conference and Exposition (APEC), Charlotte, NC, pp.1950-1955 (2015)

(17) M. Mohammadi, N. Shafiei, and M. Ordonez: "LLC synchronous rectification using coordinate modulation", in 2016 IEEE Applied Power Electronics Conference and Exposition, pp.848-853 (2016)

(18) J.W. Kim and G.W. Moon: "A New LLC Series Resonant Converter with a Narrow Switching Frequency Variation and Reduced Conduction Losses", IEEE Transactions on Power Electronics, Vol.29, No.8, pp.4278-4287 (2014)

(19) Y. Gao, K. Sun, X. Lin, and Z. Guo: "A phase-shift-based synchronous rectification scheme for bi-directional high-step-down CLLC resonant converters", 2018 IEEE Applied Power Electronics Conference and Exposition (APEC), San Antonio, TX, USA, pp.1571-1576 (2018)

(20) S. Zou, J. Lu, A. Mallik, and A. Khaligh: "Bi-Directional CLLC Converter With Synchronous Rectification for Plug-In Electric Vehicles", IEEE Trans. Ind. Appl., Vol.54, No.2, pp.998-1005 (2018)
Kai Sun (Non-member) received the B.E., M.E., and Ph.D. degrees in

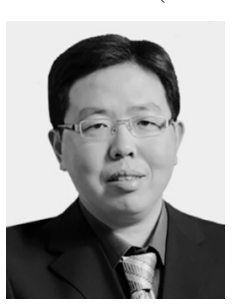
electrical engineering from Tsinghua University, Beijing, China, in 2000, 2002, and 2006, respectively. He joined the faculty of Electrical Engineering, Tsinghua University, in 2006, where he is currently an Associate Professor. From Sep 2009 to Aug 2010, he was a Visiting Scholar at Department of Energy Technology, Aalborg University, Aalborg, Denmark. From Jan to Aug 2017, he was a Visiting Professor at Department of Electrical and Computer Engineering, University of Alberta, Edmonton, Canada. His current research interests include power electronics for renewable generation systems, microgrids, and energy internet. Dr. Sun serves as the Chair of IEEE Power Electronics Society (PELS) Beijing Chapter, and leads the IEEE PELS DC Microgrids Technical Thrust. Dr. Sun serves as an Associate Editor for IEEE Transactions on Power Electronics, IEEE Journal of Emerging and Selected Topics in Power Electronics, and Journal of Power Electronics. Dr. Sun served as the TPC Vice Chair of IEEE ECCE2017 and IEEE ECCE-Asia2017. He also served as the General Co-Chair of 2018 International Future Energy Challenge (IFEC2018). He was a recipient of Delta Young Scholar Award in 2013, and Youth Award of China Power Supply Society (CPSS) in 2017.

Yucheng Gao (Non-member) received the B.E. and M.S. degrees in

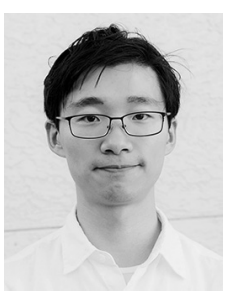
electrical engineering from Tsinghua University, Beijing, China, in 2014 and 2016, respectively. He is currently pursuing the Ph.D. degree in University of Colorado Boulder, Boulder, CO, USA. His current research interests include automotive power electronics, rectifier systems, and magnetic optimization.

Huan Chen (Non-member) received the B.E., M.E. degree in elec-

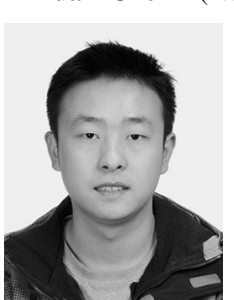
trical engineering from Tsinghua University, Beijing, China, in 2018. He is now a Ph.D. student of Electrical Engineering, Tsinghua University. His research interest is isolated bidirectional DC/DC converter. 